\title{
Macrophage migration inhibitory factor is involved in antineutrophil cytoplasmic antibody-mediated activation of C5a-primed neutrophils
}

\author{
Jian Hao ${ }^{*}$, Tiegang Lv ${ }^{\dagger}$, Liping Xu, Mao Ran and Kaili Wu
}

\begin{abstract}
Background: C5a is important for antineutrophil cytoplasmic antibody (ANCA)-mediated activation of neutrophils. The present study aimed to assess the role of macrophage migration inhibitory factor (MIF) in ANCA-mediated activation of C5a-primed neutrophils. The effects of MIF on ANCA-mediated neutrophil respiratory burst and degranulation were determined. In addition, the effect of a MIF antagonist on the activation of C5a-primed neutrophils was assessed.

Results: MIF treatment resulted in increased membrane proteinase-3 (mPR3) expression on neutrophils and enhanced myeloperoxidase (MPO) amounts in neutrophil culture supernatants. The concentration of MIF was significantly higher in the neutrophils supernatant primed with C5a (negative control: $14.2 \pm 1.16 \mathrm{ng} / \mathrm{ml}$; C5a: $45.8 \pm$ $2.8 \mathrm{ng} / \mathrm{ml}, P<0.001$ vs. negative control; $C 5 \mathrm{a}+\mathrm{lgG}: 44.8 \pm 1.93 \mathrm{ng} / \mathrm{ml}, \mathrm{P}<0.001$ vs. negative control; C5a + MPOANCA: $73.0 \pm 5.5 \mathrm{ng} / \mathrm{ml}, \mathrm{P}<0.001$ vs. C5a; and C5a + PR3-ANCA: $69.4 \pm 5.35 \mathrm{ng} / \mathrm{ml}, \mathrm{P}<0.001$ vs. C5a). MIF primed neutrophils to undergo respiratory burst and degranulation in response to ANCA. Indeed, mean fluorescence intensity (a measure of respiratory burst) was significantly higher in MIF-primed neutrophils activated with MPOANCA-positive IgG or PR3-ANCA-positive lgG compared with non-primed neutrophils. Meanwhile, a MIF antagonist reduced oxygen radical production in C5a-primed neutrophils treated with patient-derived ANCA-positive lgG.
\end{abstract}

Conclusions: MIF can prime neutrophils to undergo ANCA-mediated respiratory burst and degranulation. Blocking MIF resulted in reduced ANCA-mediated activation of C5a-primed neutrophils. These findings indicated that the interaction between MIF and C5a may contribute to ANCA-mediated neutrophil activation.

Keywords: Antineutrophil cytoplasmic antibody, C5a, Degranulation, Macrophage migration inhibitory factor, Neutrophil, Respiratory burst

\section{Background}

Granulomatosis with polyangiitis (GPA, or Wegener's granulomatosis), microscopic polyangiitis (MPA) and eosinophilic granulomatosis with polyangiitis (EGPA, or Churg-Strauss syndrome) are systemic diseases affecting small vessels featuring vessel wall segmentation with necrotizing inflammation and immunoglobulin deposition [1, 2]. GPA, MPA and EGPA are considered subsets

\footnotetext{
*Correspondence: jian_hao8865@163.com

${ }^{\dagger} J i a n$ Hao and Tiegang Lv contributed equally to this work.

Renal Division, Department of Medicine, the Affiliated Hospital of Inner

Mongolia Medical University, Huhehot 010050, Inner Mongolia, China
}

of antineutrophil cytoplasmic antibody (ANCA)-associated vasculitis (AAV) due to their association with the presence of ANCAs [1, 2]. Immunoglobulin G (IgG) autoantibodies against cytoplasmic components of neutrophils, including proteinase-3 (PR3) and myeloperoxidase (MPO), represent characteristic ANCAs [3].

The current hypothesis is that AAV pathogenesis involves neutrophils. Indeed, these cells constitute the first line of defense against bacteria and fungi. Neutrophils kill target cells using a combination of phagocytosis, oxygen radicals produced through respiratory burst, and the release of intracellular granules containing

(c) The Author(s). 2019 Open Access This article is distributed under the terms of the Creative Commons Attribution 4.0 International License (http://creativecommons.org/licenses/by/4.0/), which permits unrestricted use, distribution, and 
antimicrobial and inflammatory factors (degranulation) [4]. Lactoferrin is one of the iron-binding glycoproteins found in neutrophil granules, and can be used as a marker of neutrophil degranulation [5, 6]. Previous preclinical studies showed that ANCAs are able to stimulate respiratory burst and degranulation in primed neutrophils. The above effects are considered important contributors to the development of AAVs [7-11]. Indeed, the pathogenic potential of ANCAs has been demonstrated in a mouse model of vasculitis induced by antiMPO antibodies [12]. Furthermore, animal studies demonstrated that neutrophils are the main cellular effectors in AAVs $[12,13]$. Nevertheless, previous clinical and in vivo studies have implicated different pathways in the pathogenesis of AAVs [14-18]. It was shown that priming of neutrophils by C5a is necessary for an ANCAinduced respiratory burst to occur [19]. Although therapies targeting C5a have shown some initial promise [20], our knowledge of the key molecules and physiological events activating C5a-primed neutrophils by ANCAs is still limited at best.

Macrophage migration inhibitory factor (MIF) represents a proinflammatory cytokine with important roles in the innate and adaptive immune systems [21]. The cytoplasm of human nucleated cells contains MIF, which is released in response to cellular stress, leading to the activation of the CD74/CD44 receptor complex [21-24]. Hence, it was hypothesized that MIF plays important roles in a number of diseases, including chronic renal disease [25], asthma [26], rheumatoid arthritis [27], inflammatory bowel diseases [28, 29], systemic lupus erythematosus [30, 31] and crescentic glomerulonephritis [30]. MIF enhances the chemotactic responses and survival of neutrophils [32,33], and is therefore involved in AAVs [34, 35]. C5a stimulates neutrophils to produce MIF during sepsis, and C5a receptor inhibition decreases the release of MIF during the initial stages of sepsis [36].

It was previously reported that active AAV cases have high plasma levels of MIF, while MIF-primed neutrophils could be stimulated by MPO-ANCA-positive IgG or PR3-ANCA-positive IgG to undergo respiratory burst and degranulation [37]. Nevertheless, MIF's function in C5a-primed neutrophils remains unknown. Based on the above findings, we hypothesized that MIF released from C5a-primed neutrophils would boost neutrophil activation and contribute to ANCA-induced respiratory burst and degranulation in these cells. Therefore, the present study assessed the effect of MIF on ANCA-associated activation of C5a-primed neutrophils.

\section{Materials and methods}

\section{IgG preparation}

Cases of active MPO-ANCA- or PR3-ANCA-positive primary AAV (none had both ailments) were recruited, and ANCA-positive IgG molecules were extracted from their plasma [38, 39]. Healthy volunteers were recruited, and normal IgG was obtained [40, 41]. We controlled the amount of ANCA-positive IgG (total IgG), and the amount of ANCA-IgG was kept consistent for each individual patient in the experiment. LPS amounts in ANCA-positive IgG samples were $<0.1 \mathrm{ng} / \mathrm{ml}$.

\section{Neutrophil isolation}

Neutrophils from heparin-treated venous blood obtained from healthy individuals were isolated by density gradient centrifugation using Lymphoprep (Nycomed, Norway). Red blood cell lysis was performed with chilled $\mathrm{NH}_{4} \mathrm{Cl}$ buffer, and neutrophils (purity $>95 \%$ ) underwent washing with $\mathrm{Ca}^{2+} / \mathrm{Mg}^{2+}$-free Hanks balanced salt solution (HBSS-/-; Chemical Reagents, China) and resuspended at $2.5 \times 10^{7}$ cells $/ \mathrm{ml}$ in HBSS containing calcium and magnesium (HBSS+/+; Chemical Reagents). This suspension was used in subsequent experiments [40].

This study followed the Declaration of Helsinki, and had approval from the Clinical Research Ethics Committee of the Affiliated Hospital of Inner Mongolia Medical College. Each participant or donor provided written informed consent.

\section{Membrane expression of PR3 and MPO in neutrophils}

PR3 and MPO levels on the neutrophil surface were examined by flow cytometry. C5a ( $100 \mathrm{ng} / \mathrm{ml}$ for $15 \mathrm{~min}$ at $37^{\circ} \mathrm{C}$; Biovision, USA) primed and control neutrophils were administered MIF ( $50 \mathrm{ng} / \mathrm{ml}$; Sigma-Aldrich, USA) or not (buffer without MIF) for $30 \mathrm{~min}$ at $37^{\circ} \mathrm{C}$. All subsequent procedures were carried out on ice; all washes were performed with $\mathrm{HBSS}+/+$ containing $1 \%$ bovine serum albumin (BSA). Heat-denatured goat IgG $(0.5 \mathrm{mg} /$ $\mathrm{ml}$ ) was incubated with the cells for $15 \mathrm{~min}$ for Fcy receptor saturation. The neutrophils underwent staining for 30 min with mouse monoclonal IgG1 antibodies targeting human PR3 (WGM2; Abcam, UK) and MPO (2C7; Abcam), respectively, or control IgG1 antibodies (BioLegend, USA). This was followed by incubation with phycoerythrin (PE)-conjugated goat anti-mouse antibodies (Abcam) and $0.5 \mathrm{mg} / \mathrm{ml}$ heat-treated goat IgG. The expression levels of ANCA antigens were evaluated flow-cytometrically based on PE fluorescence on a BD FACScan (Becton Dickinson, USA). A total of 10,000 cells were analyzed per specimen. PR3 and MPO levels were assessed as mean fluorescence intensity (MFI) values of specific signals. In certain experiments, neutrophils underwent pre-treatment with the small-molecule MIF antagonist (S,R)3-(4-hydroxyphenyl)-4,5-dihydro-5isoxazole acetic acid methyl ester (ISO-1; Tocris Bioscience, USA) [42, 43] or vehicle (dimethyl sulfoxide, DMSO) prior to other interventions [44]. 
Measurement of MPO levels in cell culture supernatants A commercial enzyme-linked immunosorbent assay (ELISA) (USCNK, China) kit was used for measuring MPO levels in the supernatants of neutrophils treated with MIF and/or C5a, as directed by the manufacturer. Absorbance was measured at $450 \mathrm{~nm}$ on a spectrophotometer.

\section{Measurement of MIF levels in cell culture supernatants}

A commercial kit (Abcam, UK) was used for measuring MIF levels in the supernatant of neutrophil cultures treated with C5a $(100 \mathrm{ng} / \mathrm{ml})$ and ANCA-positive IgG or buffer, according to the manufacturer's instructions. The absorbance was measured at $450 \mathrm{~nm}$.

\section{Respiratory burst assessment}

The production of reactive oxygen species was estimated based on dihydrorhodamine (DHR, non-fluorescent) oxidation into rhodamine (green fluorescence). Neutrophils were administered $0.05 \mathrm{mM}$ DHR123 (Sigma-Aldrich) for $10 \mathrm{~min}$ at $37^{\circ} \mathrm{C}$, with $2 \mathrm{mM} \mathrm{NaN}_{3}$ supplemented for preventing intracellular degradation of $\mathrm{H}_{2} \mathrm{O}_{2}$. Then, the cells were sequentially administered $\operatorname{MIF}(50 \mathrm{ng} / \mathrm{ml})$ or C5a (100 ng/ml) [45], and normal or patient-derived ANCApositive IgG $(200 \mu \mathrm{g} / \mathrm{ml})$ for $1 \mathrm{~h}$ at $37^{\circ} \mathrm{C}$. Reactions were terminated by addition of $1 \mathrm{ml}$ of ice-cold HBSS containing 1\% BSA. Data (10,000 cells per sample) were collected by flow cytometry on a BD FACScan. MFI values determined for all experimental conditions represented the amounts of reactive oxygen species produced [40, 41].

\section{ANCA-induced degranulation}

Neutrophils treated with MIF and/or C5a were administered MPO-ANCA-positive, PR3-ANCA-positive, or normal IgG for $1 \mathrm{~h}$, with control cells treated with the buffer. Some groups of cells also underwent pretreatment with ISO-1 or DMSO (15 min on ice). Supernatant lactoferrin content was detected with an ELISA kit (USCNK, China), as directed by the manufacturer.

\section{Statistical analysis}

The Shapiro-Wilk test was employed to assess data normality. Quantitative data are mean \pm standard deviation (SD) (normal distribution) or median and range (skewed distribution). Student's t test and the Mann-Whitney U test were used to compare data with normal and nonnormal distributions, respectively. $P<0.05$ indicated statistical significance. All analyses were carried out with SPSS 16.0 (SPSS, USA).

\section{Results}

MIF increases mPR3 levels on neutrophils and MPO amounts in culture supernatants

Neutrophil expression of mPR3 and MPO levels in cell supernatants were measured using neutrophils obtained from five healthy individuals, administered 0 and $50 \mathrm{ng} / \mathrm{ml}$ MIF, respectively. The mPR3 expression levels were markedly elevated in MIF-primed neutrophils compared with control cells $(382.8 \pm 13.8$ vs. $156.2 \pm 9.98, P<0.001$ ) (Fig. 1a). Furthermore, MPO amounts were starkly higher in supernatants from MIF-primed neutrophils compared with the control value $(1752.1 \pm 83.7 \mathrm{ng} / \mathrm{ml}$ vs. $632.8 \pm 25.27 \mathrm{ng} / \mathrm{ml}, P<$ 0.001) (Fig. 1b).

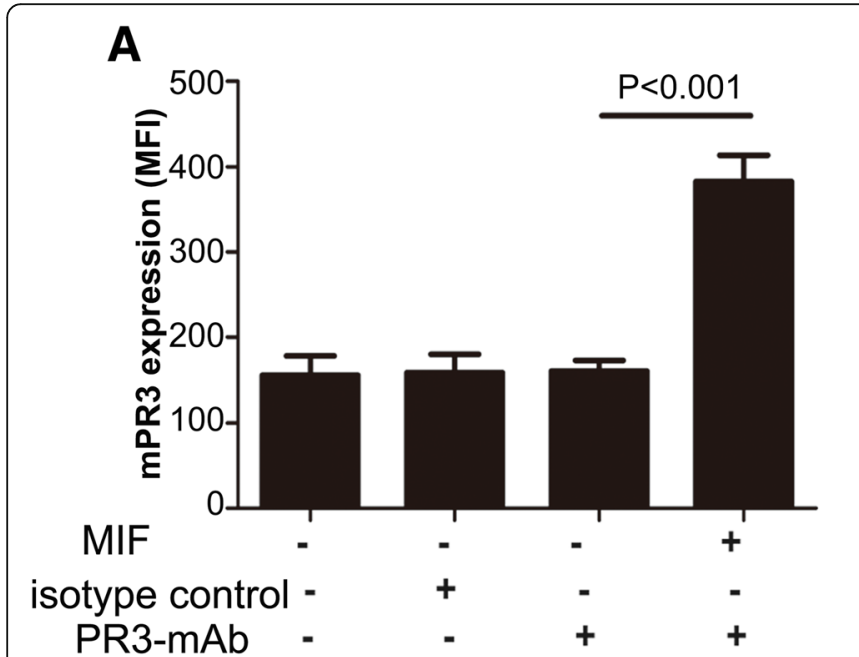

B

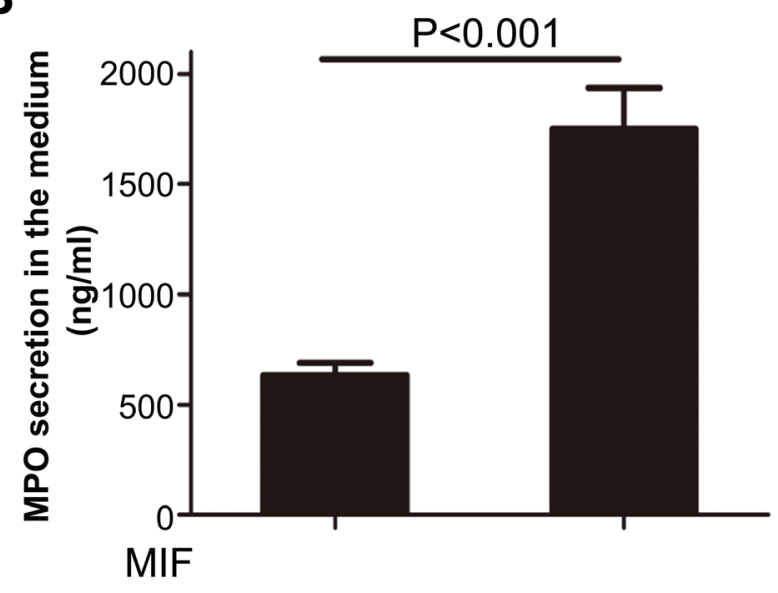

Fig. 1 Macrophage migration inhibitory factor (MIF) enhances the translocation of antineutrophil cytoplasmic antibody (ANCA) antigens. a Expression of membrane proteinase-3 (mPR3) on neutrophils obtained from five healthy donors. mAb, monoclonal antibody; MFI, mean fluorescence intensity. b Myeloperoxidase (MPO) levels in culture supernatants of neutrophils obtained from five healthy donors. Bars represent mean \pm standard deviation of measurements made in five independent experiments 
ANCA stimulates MIF-treated neutrophils to undergo respiratory burst and degranulation

ANCA-positive IgGs (obtained from 5 active MPOANCA- and 3 active PR3-ANCA-positive vasculitis cases) were used to assess whether ANCA would induce respiratory burst in MIF-treated neutrophils. MIF was used at $50 \mathrm{ng} / \mathrm{ml}$, which increased the expression levels of mPR3 on neutrophils. In comparison with untreated cells, MIF-primed neutrophils administered MPOANCA-positive IgG $(389.4 \pm 11.72$ vs. $254.8 \pm 12.8, P<$ $0.001)$ or PR3-ANCA-positive IgG (394.8 \pm 11.71 vs. $254.8 \pm 12.8, P<0.001)$ showed markedly elevated MFI values (Fig. $2 \mathrm{a}$ and b). Meanwhile, MIF, ANCA-IgG, or normal IgG caused no overt respiratory burst, and neither did MIF combined with normal IgG.

Degranulation levels were evaluated by determination of lactoferrin amounts in supernatants from neutrophils treated with MIF and ANCA-positive IgGs. In comparison with unstimulated cells, MIF-treated neutrophils exposed to MPO-ANCA-positive IgG $(1515.0 \pm 44.94 \mathrm{ng} /$ $\mathrm{ml}$ vs. $499.2 \pm 18.64 \mathrm{ng} / \mathrm{ml}, P<0.001)$ or $P R 3-A N C A$ positive IgG $(1613.0 \pm 49.52 \mathrm{ng} / \mathrm{ml}$ vs. $499.2 \pm 18.64 \mathrm{ng} /$ $\mathrm{ml}, P<0.001)$ showed markedly increased lactoferrin amounts in supernatants. Although degranulation was somewhat stimulated in neutrophils administered ANCA-IgG only, normal IgG only or MIF combined

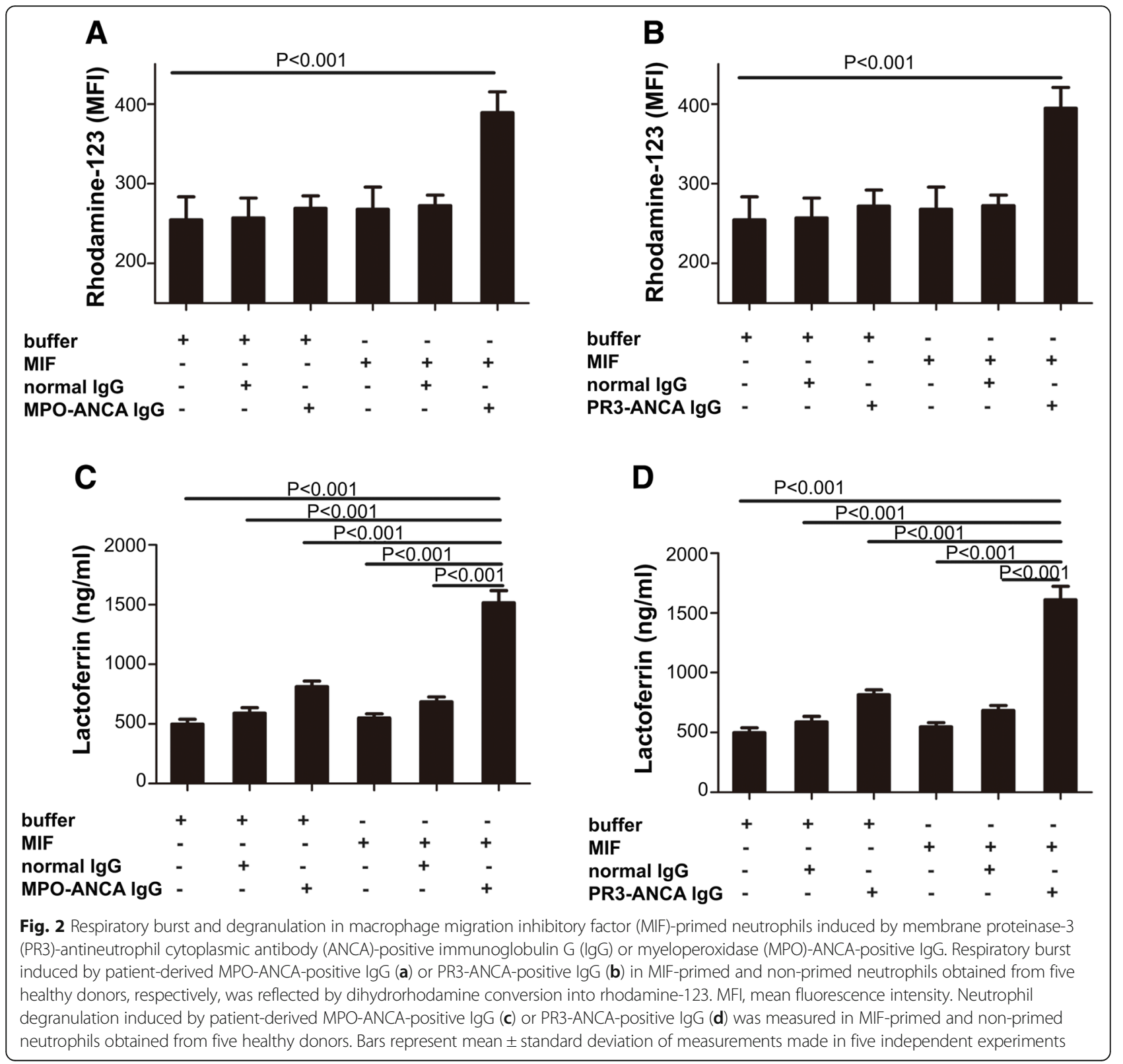


with normal IgG, further significant increases were observed following exposure to MPO-ANCA- or MPOANCA-positive IgG. In contrast, degranulation levels did not differ between neutrophils treated with normal IgG alone and cells administered MIF combined with normal IgG (Fig. 2c and d).

MIF levels in the supernatants of C5a-primed neutrophil Neutrophils were incubated with C5a (100 ng/L) and MIF concentration in the supernatant was detected by ELISA. The concentration of MIF was significantly higher in the neutrophils supernatant primed with $\mathrm{C} 5 \mathrm{a}$ (negative control: $14.2 \pm 1.16$; C5a: $45.8 \pm 2.8, P<0.001$ vs. negative control; C5a + IgG: $44.8 \pm 1.93, \mathrm{P}<0.001$ vs. negative control; C5a + MPO-ANCA: $73.0 \pm 5.5, \quad \mathrm{P}<$ 0.001 vs. C5a; and C5a + PR3-ANCA: $69.4 \pm 5.35 \mathrm{ng} / \mathrm{ml}$, $\mathrm{P}<0.001$ vs. C5a) (Fig. 3).

\section{A MIF antagonist inhibits ANCA-associated respiratory burst and degranulation in C5a-treated neutrophils} MFI values for DHR oxidation were elevated in C5atreated neutrophils administered MPO-ANCA- (902.6 \pm 34.3 vs. $496.8 \pm 25.4, P<0.001)$ or PR3-ANCA- $(899.8 \pm$ 26.85 vs. $496.8 \pm 25.4, P<0.001)$ positive IgG, in comparison with non-treated cells (Fig. 4a). Pre-treatment

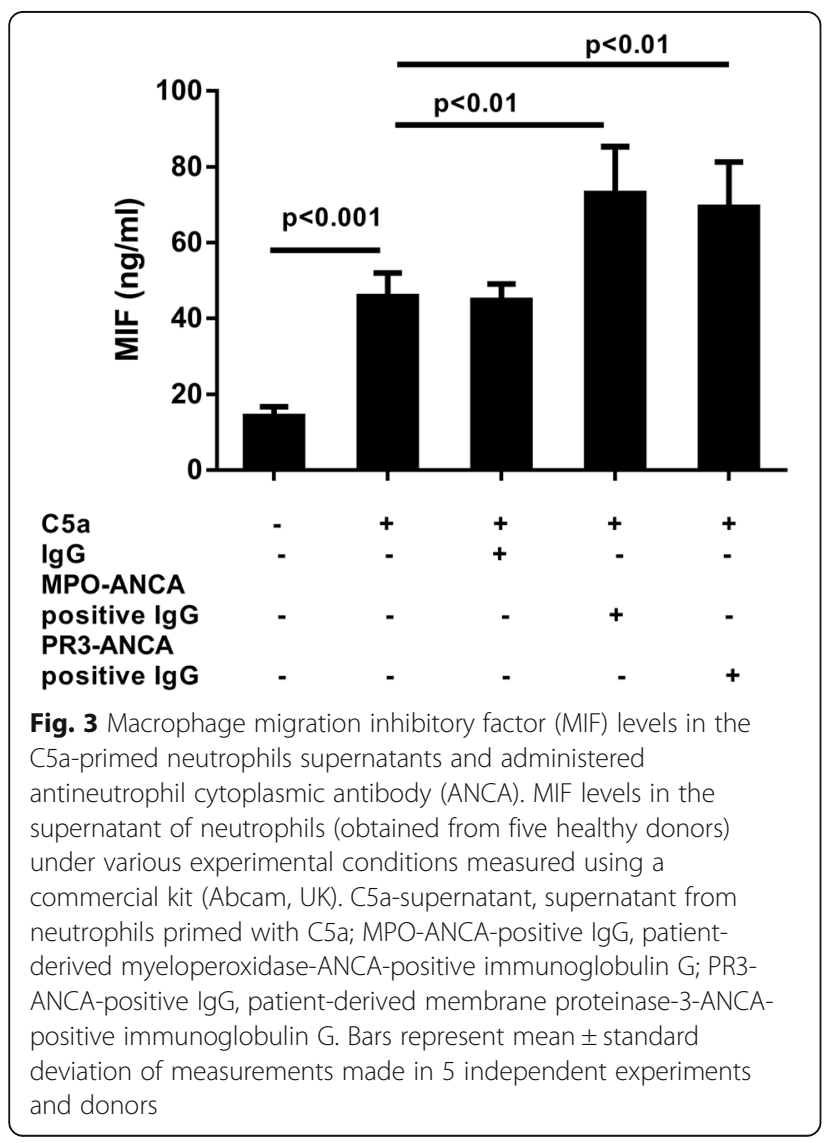

with $5 \mu \mathrm{M}$ or $10 \mu \mathrm{M}$ ISO-1 (a MIF antagonist) for $5 \mathrm{~min}$ did not significantly reduce MFI values for DHR oxidation. However, pre-treatment with $10 \mu \mathrm{M}$ ISO- 1 for 15 min resulted in decreased production of oxygen radicals in C5a-treated neutrophils exposed to ANCA-positive IgG. Pre-treatment of C5a-primed cells with ISO-1 had no significant effect on mPR3 expression and MPO secretion (data not shown). In C5a-treated cells administered MPO-ANCA-positive IgG, ISO-1 reduced MFI values for DHR oxidation from $902.6 \pm 34.32$ (in the absence of ISO-1) to $677.6 \pm 25.9(P<0.001)$ (Fig. $4 \mathrm{~b})$. In cells treated with PR3-ANCA-positive IgG, MFI values were decreased by ISO-1 from $899.8 \pm 26.85$ to $653.6 \pm$ $36.52(P<0.001)$ (Fig. 4b).

Pretreatment with ISO-1 resulted in significantly decreased amounts of lactoferrin released in response to MPO-ANCA- or PR3-ANCA-positive IgG. Lactoferrin levels in cell supernatants rose from $602.4 \pm 37.5 \mathrm{ng} / \mathrm{ml}$ in non-primed neutrophils to $1569.0 \pm 48.2 \mathrm{ng} / \mathrm{ml}$ in C5a-treated cells administered MPO-ANCA-positive IgG $(P<0.001)$, and $1562.0 \pm 73.9 \mathrm{ng} / \mathrm{ml}$ in C5a-treated cells exposed to PR3-ANCA-positive IgG $(P<0.001)$. However, upon pre-incubation with ISO-1, lactoferrin amounts in C5a-treated neutrophils were only slightly increased to $886.8 \pm 37.1 \mathrm{ng} / \mathrm{ml}$ after treatment with MPO-ANCA-positive IgG $(P<0.001$ vs. value in the absence of ISO-1) and $925.2 \pm 30.0 \mathrm{ng} / \mathrm{ml}$ in cells treated with PR3-ANCA-positive IgG $(P<0.001$ vs. value in the absence of ISO-1) (Fig. 4c).

\section{Supernatants of C5a-treated neutrophil cultures can} cause unstimulated neutrophils to undergo ANCA-related respiratory burst and degranulation

Next, neutrophils were primed using supernatants obtained from C5a-stimulated neutrophil cultures. In comparison with non-treated neutrophils, MFI values for DHR oxidation (i.e. oxygen radical production) were significantly higher in supernatant-treated cells administered MPO-ANCA- $(487.0 \pm 34.9$ vs. $252.4 \pm 28.5, P<0.001)$ or PR3-ANCA- (512.2 \pm 61.5 vs. $252.4 \pm 28.5, P<0.001)$ positive IgG. Pre-incubation of supernatant-treated neutrophils with ISO-1 resulted in decreased MFI values in cells treated with MPO-ANCA- (from 487.0 \pm 34.9 in the absence of ISO- 1 to $377.0 \pm 39.9$ in its presence, $P<0.001)$ or PR3-ANCA- (from 512.2 \pm 61.5 in the absence of ISO1 to $402.8 \pm 55.9$ in its presence, $P<0.001)$ positive IgG (Fig. 5a).

Pre-treatment with the MIF antagonist also suppressed lactoferrin release in response to MPO-ANCA- or PR3ANCA-positive IgG. Lactoferrin amounts in supernatants rose from $555.0 \pm 75.3 \mathrm{ng} / \mathrm{ml}$ in non-primed neutrophils to $1371.0 \pm 140.6 \mathrm{ng} / \mathrm{ml}$ and $1352 \pm 178.4 \mathrm{ng} / \mathrm{ml}$ in supernatanttreated cells administered MPO-ANCA- and PR3-ANCApositive IgGs, respectively (both $P<0.001$ ). In supernatant- 


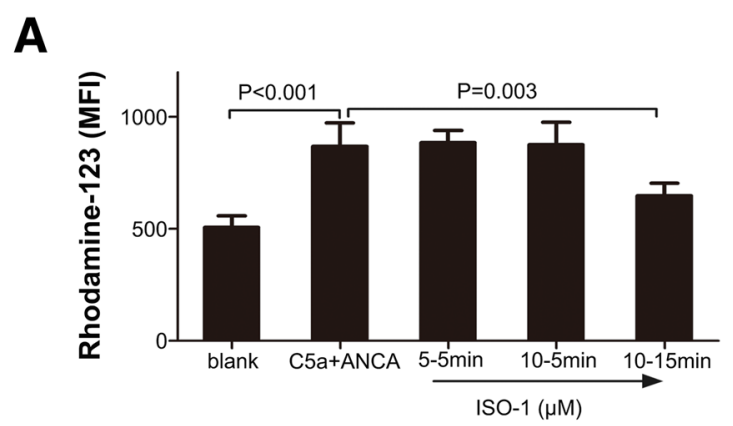

B
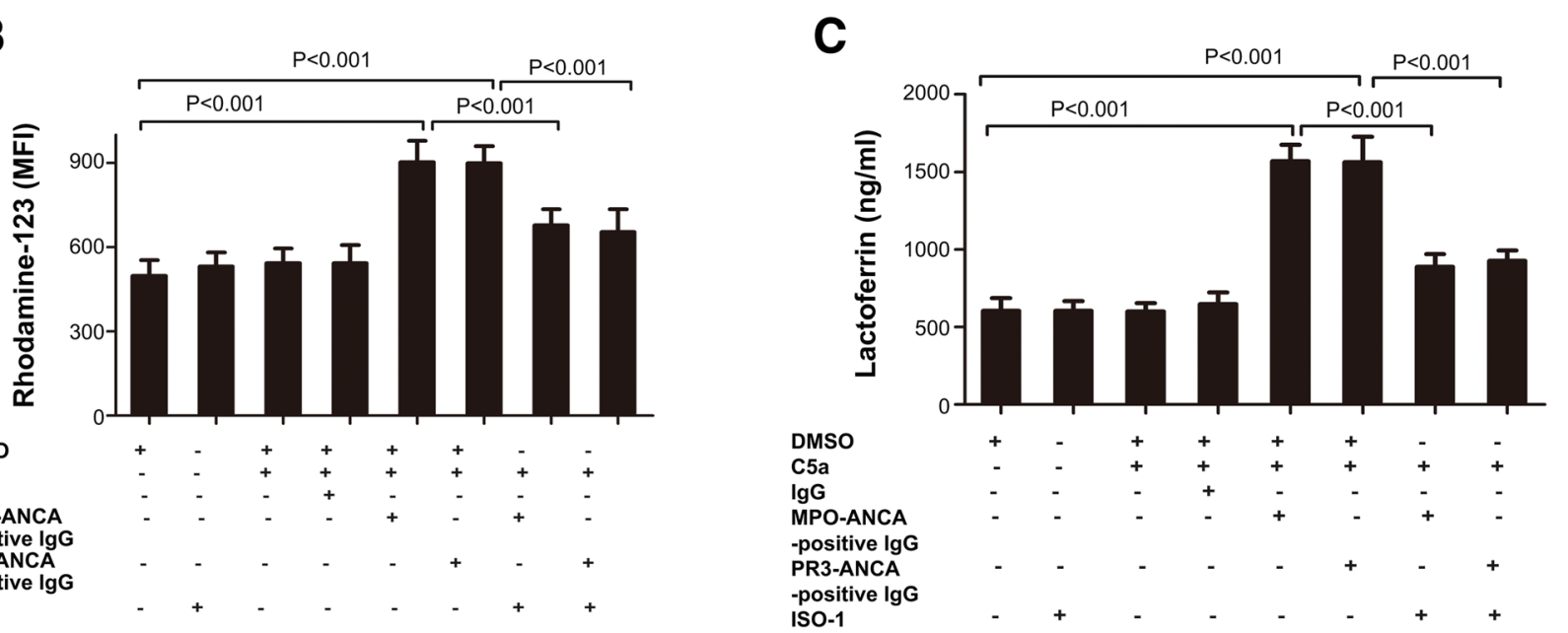

Fig. 4 A macrophage migration inhibitory factor (MIF) antagonist inhibits antineutrophil cytoplasmic antibody (ANCA)-induced respiratory burst and degranulation in C5a-primed neutrophils. a Neutrophil respiratory burst was reflected by dihydrorhodamine-123 conversion into rhodamine123. Neutrophils obtained from five healthy donors were pre-incubated with various concentrations of (S,R)3-(4-hydroxyphenyl)-4,5-dihydro-5isoxazole acetic acid methyl ester (ISO-1) for different time periods, primed with MIF and stimulated with ANCA. Blank, untreated neutrophils; C5a + ANCA, neutrophils primed with C5a and stimulated with ANCA; 5-5 min, neutrophils pre-incubated with $5 \mu \mathrm{M}$ ISO-1 for 5 min and then treated with C5a and ANCA; 10-5 min, neutrophils pre-incubated with $10 \mu \mathrm{M}$ ISO-1 for 5 min and then treated with C5a and ANCA; 10-15 min, neutrophils pre-incubated with $10 \mu \mathrm{M}$ ISO-1 for $15 \mathrm{~min}$ and then treated with C5a and ANCA. MFI, mean fluorescence intensity. b Respiratory burst in neutrophils (obtained from five healthy donors) under various experimental conditions, reflected by dihydrorhodamine-123 conversion into rhodamine-123. DMSO, dimethyl sulfoxide (control); IgG, normal immunoglobulin G; ISO-1, (S,R)3-(4-hydroxyphenyl)-4,5-dihydro-5-isoxazole acetic acid methyl ester (MIF antagonist); MFI, mean fluorescence intensity; MPO-ANCA-positive IgG, patient-derived myeloperoxidase-ANCApositive immunoglobulin G; PR3-ANCA-positive lgG, patient-derived membrane proteinase-3-ANCA-positive immunoglobulin G. c Degranulation of neutrophils (obtained from five healthy donors) under various experimental conditions, determined from measurements of lactoferrin amounts in cell supernatants. DMSO, dimethyl sulfoxide (control); lgG, normal immunoglobulin G; ISO-1, (S,R)3-(4-hydroxyphenyl)-4,5-dihydro-5-isoxazole acetic acid methyl ester (MIF antagonist); MPO-ANCA-positive lgG, patient-derived myeloperoxidase-ANCA-positive immunoglobulin G; PR3-ANCApositive IgG, patient-derived membrane proteinase-3-ANCA-positive immunoglobulin G. Bars represent mean \pm standard deviation of measurements made in 5 independent experiments

primed neutrophils, pre-incubation with ISO-1 resulted in decreased lactoferrin amounts to $854.5 \pm 65.6 \mathrm{ng} / \mathrm{ml}$ and $822.0 \pm 45.73 \mathrm{ng} / \mathrm{ml}$ in cells treated with MPO-ANCA- and PR3-ANCA-positive IgGs, respectively (both $P<0.001$ vs. respective values in the absence of ISO-1) (Fig. 5b).

\section{Discussion}

Neutrophils are an important cell type involved in AAV $[12,13]$. ANCAs probably have a direct role in the pathogenesis of AAVs by stimulating respiratory burst and degranulation in activated neutrophils [7-11]. Clinical and in vivo data indicate complement activation through the alternative pathway is also critical in AAV development [14-19, 44, 46, 47]. Among others, C5a can prime neutrophils for respiratory burst induced by ANCA [19]. Consistently, we previously demonstrated that translocation of ANCA antigens and ANCA-related respiratory burst in neutrophils are enhanced by recombinant C5a [45]. MIF is an immunomodulatory factor that regulates chemotaxis and survival in neutrophils $[32,33]$, and is involved in AAV $[34,35]$ and other autoimmune diseases [26-31]. Notably, elevated levels of plasma MIF were reported in patients with active AAV [37]. Furthermore, respiratory burst and degranulation by MIF-treated neutrophils are stimulated by MPOANCA- and PR3-ANCA-positive IgGs [37]. A previous 


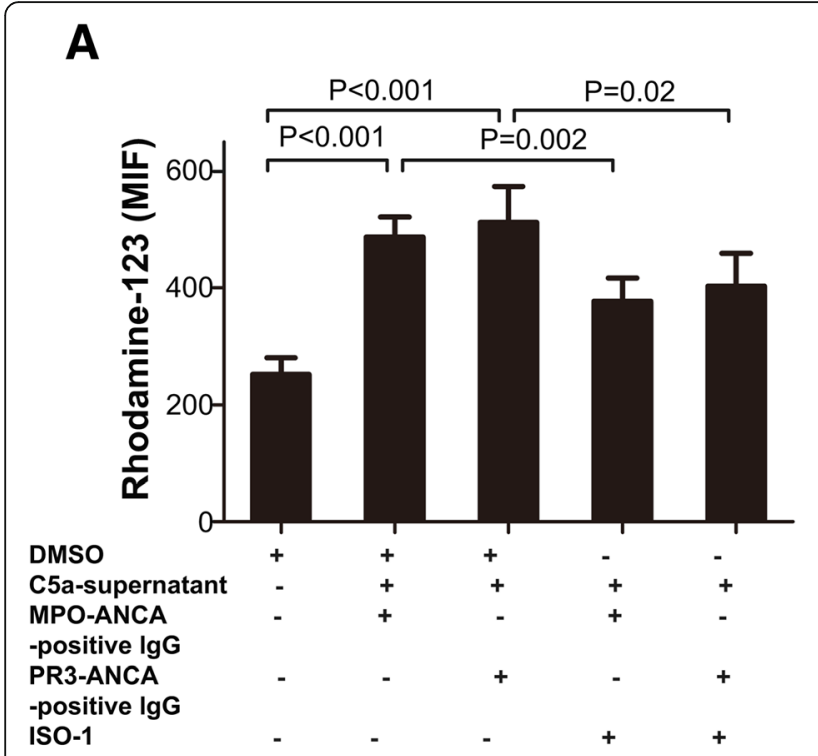

B

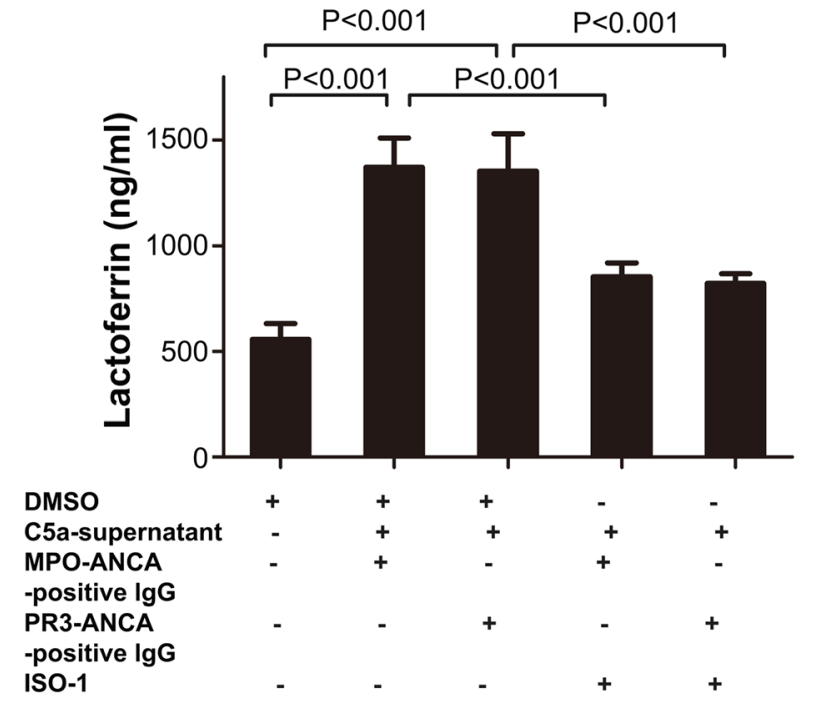

Fig. 5 A macrophage migration inhibitory factor (MIF) antagonist inhibits respiratory burst and degranulation in neutrophils primed with culture supernatants from C5a-stimulated neutrophils and administered antineutrophil cytoplasmic antibody (ANCA). a Respiratory burst in neutrophils (obtained from five healthy donors) under various experimental conditions measured from dihydrorhodamine-123 conversion into rhodamine123. DMSO, dimethyl sulfoxide (control); C5a-supernatant, supernatant from neutrophils primed with C5a; ISO-1, (S,R)3-(4-hydroxyphenyl)-4,5dihydro-5-isoxazole acetic acid methyl ester (MIF antagonist); MFI, mean fluorescence intensity; MPO-ANCA-positive IgG, patient-derived myeloperoxidase-ANCA-positive immunoglobulin G; PR3-ANCA-positive IgG, patient-derived membrane proteinase-3-ANCA-positive immunoglobulin G. b Degranulation of neutrophils (obtained from five healthy donors) under various experimental conditions, determined from measurements of lactoferrin levels in culture supernatants. DMSO, dimethyl sulfoxide (control); C5a-supernatant, supernatant from neutrophils primed with C5a; ISO-1, (S,R)3-(4-hydroxyphenyl)-4,5-dihydro-5-isoxazole acetic acid methyl ester (MIF antagonist); MPO-ANCA-positive IgG, patient-derived myeloperoxidase-ANCA-positive immunoglobulin G; PR3-ANCA-positive IgG, patient-derived membrane proteinase-3-ANCApositive immunoglobulin $G$. Bars represent mean \pm standard deviation of measurements made in 5 independent experiments and donors

study showed that C5a induces MIF production by neutrophils in sepsis [36], although the exact interaction between C5a and MIF as well as their roles in AAV remain mostly unknown. Therefore, the current study aimed to assess MIF's role in the activation of C5a-primed neutrophils by ANCAs.

The present study indicated that neutrophils are an important source of MIF, and therefore may have a critical function in MIF release in pathologic conditions such as AAV, corroborating previous findings. MIF contributes to the pathogenesis of LPS-induced acute lung injury (ALI), and could be a therapeutic target in ALI [48]. Of note, MIF could also be a therapeutic target in a number of immune-related pathologies such as asthma [26], rheumatoid arthritis [27], chronic colitis [28], ulcerative colitis [29], glomerulonephritis [30], and lupus erythematosus [31], highlighting the possible clinical significance of the present study.

A previous report showed that patients with GPA or MPA have high MIF levels compared with those in remission [35]. Furthermore, a recent study by our group revealed that almost all patients with active MPA have high plasma levels of MIF [37]. Increased translocation of ANCA antigens is an important characteristic of neutrophils primed with MIF. ANCA-positive IgGs from patients with MPA can be used to further prime neutrophils and induce respiratory burst and degranulation. Therefore, we hypothesized that MIF promotes inflammation and disease activity in AAV.

MIF production after stimulation with recombinant human $\mathrm{C} 5 \mathrm{a}$ and ANCA in neutrophils could be an important step in the initial stages of AAV. As shown above, ISO-1, a MIF antagonist, could significantly attenuate the effects of ANCA on neutrophils. Interestingly, C5a and MIF are proinflammatory factors that interact during ANCA-induced neutrophil activation. The above results are supported by a study of sepsis demonstrating that blockade or absence of the C5aR leads to a significant reduction in MIF biosynthesis [36].

Limitations of this study should be noted. First, direct measurements of MIF in cell culture supernatants were not performed. Secondly, residual C5a in cell supernatants may have contributed to the effects observed in supernatant-treated neutrophils. Thirdly, only one antagonist was used to inhibit MIF's function, and the results should be confirmed using another antagonist or the siRNA technology. Fourthly, the molecular pathways underlying the interactions among C5a, MIF and ANCAs were not explored. Therefore, additional studies are required to confirm the current findings. 


\section{Conclusions}

Overall, the current findings suggest that MIF generated by $\mathrm{C} 5 \mathrm{a}$-treated neutrophils can further cause neutrophil activation. Furthermore, MIF blockage could reduce ANCA-induced activation of C5a-primed neutrophils. Thus, interaction between $\mathrm{C} 5 \mathrm{a}$ and MIF may play a critical role during ANCA-induced activation of neutrophils. The findings presented here revealed a potential therapeutic candidate that could be targeted in order to control inflammatory injury in AAV.

\begin{abstract}
Abbreviations
AAV: ANCA)-associated vasculitis; ALI: Acute lung injury; ANCA: Antineutrophil cytoplasmic antibody; BSA: Bovine serum albumin; DHR: Dihydrorhodamine; DMSO: Dimethyl sulfoxide; EGPA: Eosinophilic granulomatosis with polyangiitis; ELISA: Enzyme-linked immunosorbent assay; GPA: Granulomatosis with polyangiitis; HRP: Horseradish peroxidase IgG: Immunoglobulin G; MFI: Mean fluorescence intensity; MIF: Migration inhibitory factor; MPA: Microscopic polyangiitis; MPO: Myeloperoxidase; mPR3: Membrane proteinase-3; PE: Phycoerythrin
\end{abstract}

\section{Acknowledgements}

Not applicable.

\section{Authors' contributions}

$\mathrm{JH}$ and TGL conceived and supervised the study; KLW and MR performed the experiments; LPX and TGL analyzed the data; JH and TGL wrote the manuscript; JH and LPX revised the manuscript. All authors reviewed the results and approved the final version of the manuscript.

\section{Funding}

This study was supported by the National Natural Science Foundation (No. 81460145) and the Inner Mongolia Natural Science Foundation (2018MS08105). The funders had no role in study design, data collection and analysis, decision to publish, or preparation of the manuscript.

\section{Availability of data and materials}

The datasets used and/or analysed during the current study are available from the corresponding author on reasonable request.

\section{Ethics approval and consent to participate}

This research was performed in accordance with the Declaration of Helsinki and approved by the Clinical Research Ethics Committee of the Affiliated Hospital of Inner Mongolia Medical College. Each participant provided written informed consent.

\section{Consent for publication}

Not applicable.

\section{Competing interests}

The authors declare that they have no conflict of interest.

Received: 29 September 2018 Accepted: 24 June 2019

Published online: 27 June 2019

\section{References}

1. Yates M, Watts R. ANCA-associated vasculitis. Clin Med (Lond). 2017;17:60-4.

2. Jennette JC, Falk RJ. Small-vessel vasculitis. N Engl J Med. 1997;337:1512-23.

3. Jennette JC, Falk RJ, Bacon PA, Basu N, Cid MC, Ferrario F, Flores-Suarez LF, Gross WL, Guillevin L, Hagen EC, et al. 2012 revised international Chapel Hill consensus conference nomenclature of Vasculitides. Arthritis Rheum. 2013; 65:1-11.

4. Bertram A, Ley K. Protein kinase $\mathrm{C}$ isoforms in neutrophil adhesion and activation. Arch Immunol Ther Exp. 2011;59:79-87.

5. Lonnerdal B, lyer S. Lactoferrin: molecular structure and biological function. Annu Rev Nutr. 1995;15:93-110.

6. Baker EN, Baker HM. Molecular structure, binding properties and dynamics of lactoferrin. Cell Mol Life Sci. 2005;62:2531-9.
7. Falk RJ, Terrell RS, Charles LA, Jennette JC. Anti-neutrophil cytoplasmic autoantibodies induce neutrophils to degranulate and produce oxygen radicals in vitro. Proc Natl Acad Sci U S A. 1990;87:4115-9.

8. Charles LA, Caldas ML, Falk RJ, Terrell RS, Jennette JC. Antibodies against granule proteins activate neutrophils in vitro. J Leukoc Biol. 1991;50:539-46.

9. Keogan MT, Esnault VL, Green AJ, Lockwood CM, Brown DL. Activation of normal neutrophils by anti-neutrophil cytoplasm antibodies. Clin Exp Immunol. 1992;90:228-34.

10. Mulder AH, Heeringa P, Brouwer E, Limburg PC, Kallenberg CG. Activation of granulocytes by anti-neutrophil cytoplasmic antibodies (ANCA): a fc gamma Rll-dependent process. Clin Exp Immunol. 1994;98:270-8.

11. Hewins P, Morgan MD, Holden N, Neil D, Williams JM, Savage CO, Harper L. IL-18 is upregulated in the kidney and primes neutrophil responsiveness in ANCA-associated vasculitis. Kidney Int. 2006;69:605-15.

12. Xiao H, Heeringa $P$, Hu P, Liu Z, Zhao M, Aratani Y, Maeda N, Falk R, Jennette JC Antineutrophil cytoplasmic autoantibodies specific for myeloperoxidase cause glomerulonephritis and vasculitis in mice. J Clin Invest. 2002;110:955-63.

13. Xiao H, Heeringa P, Liu Z, Huugen D, Hu P, Maeda N, Falk RJ, Jennette JC. The role of neutrophils in the induction of glomerulonephritis by antimyeloperoxidase antibodies. Am J Pathol. 2005;167:39-45.

14. Gou SJ, Yuan J, Chen M, Yu F, Zhao MH. Circulating complement activation in patients with anti-neutrophil cytoplasmic antibody-associated vasculitis. Kidney Int. 2013:83:129-37.

15. Huugen D, van Esch A, Xiao H, Peutz-Kootstra CJ, Buurman WA, Tervaert JW Jennette JC, Heeringa P. Inhibition of complement factor $\mathrm{C} 5$ protects against anti-myeloperoxidase antibody-mediated glomerulonephritis in mice. Kidney Int. 2007;71:646-54.

16. Xiao $H$, Schreiber $A$, Heeringa $P$, Falk RJ, Jennette JC. Alternative complement pathway in the pathogenesis of disease mediated by antineutrophil cytoplasmic autoantibodies. Am J Pathol. 2007:170:52-64.

17. Chen $M$, Xing GQ, Yu F, Liu G, Zhao MH. Complement deposition in renal histopathology of patients with ANCA-associated pauci-immune glomerulonephritis. Nephrol Dial Transplant. 2009;24:1247-52

18. Xing GQ, Chen M, Liu G, Heeringa P, Zhang JJ, Zheng X, E J, Kallenberg CG, Zhao $\mathrm{MH}$. Complement activation is involved in renal damage in human antineutrophil cytoplasmic autoantibody associated pauci-immune vasculitis. J Clin Immunol. 2009;29:282-91.

19. Schreiber A, Xiao H, Jennette JC, Schneider W, Luft FC, Kettritz R. C5a receptor mediates neutrophil activation and ANCA-induced glomerulonephritis. J Am Soc Nephrol. 2009:20:289-98.

20. Woodruff TM, Nandakumar KS, Tedesco F. Inhibiting the C5-C5a receptor axis. Mol Immunol. 2011:48:1631-42.

21. Leng L, Metz CN, Fang Y, Xu J, Donnelly S, Baugh J, Delohery T, Chen Y, Mitchell RA, Bucala R. MIF signal transduction initiated by binding to CD74. J Exp Med. 2003;197:1467-76.

22. Fan C, Rajasekaran D, Syed MA, Leng L, Loria JP, Bhandari V, Bucala R, Lolis EJ. MIF intersubunit disulfide mutant antagonist supports activation of CD74 by endogenous MIF trimer at physiologic concentrations. Proc Natl Acad Sci U S A. 2013:110:10994-9.

23. Shi X, Leng L, Wang T, Wang W, Du X, Li J, McDonald C, Chen Z, Murphy JW, Lolis $E_{1}$ et al. CD44 is the signaling component of the macrophage migration inhibitory factor-CD74 receptor complex. Immunity. 2006;25:595-606.

24. Bernhagen J, Krohn R, Lue H, Gregory JL, Zernecke A, Koenen RR, Dewor M, Georgiev I, Schober A, Leng L, et al. MIF is a noncognate ligand of CXC chemokine receptors in inflammatory and atherogenic cell recruitment. Nat Med. 2007;13:587-96.

25. Bruchfeld A, Wendt M, Miller EJ. Macrophage migration inhibitory factor in clinical kidney disease. Front Immunol. 2016;7:8.

26. Mizue Y, Ghani S, Leng L, McDonald C, Kong P, Baugh J, Lane SJ, Craft J, Nishihira J, Donnelly SC, et al. Role for macrophage migration inhibitory factor in asthma. Proc Natl Acad Sci U S A. 2005;102:14410-5.

27. Leech M, Metz C, Hall P, Hutchinson P, Gianis K, Smith M, Weedon H, Holdsworth SR, Bucala R, Morand EF. Macrophage migration inhibitory factor in rheumatoid arthritis: evidence of proinflammatory function and regulation by glucocorticoids. Arthritis Rheum. 1999;42:1601-8.

28. de Jong YP, Abadia-Molina AC, Satoskar AR, Clarke K, Rietdijk ST, Faubion WA Mizoguchi E, Metz CN, Alsahli M, ten Hove T, et al. Development of chronic colitis is dependent on the cytokine MIF. Nat Immunol. 2001;2:1061-6.

29. Murakami H, Akbar SM, Matsui H, Onji M. Macrophage migration inhibitory factor in the sera and at the colonic mucosa in patients with ulcerative colitis: clinical implications and pathogenic significance. Eur J Clin Investig. 2001;31:337-43. 
30. Lan HY, Yang N, Nikolic-Paterson DJ, Yu XQ, Mu W, Isbel NM, Metz CN, Bucala R, Atkins RC. Expression of macrophage migration inhibitory factor in human glomerulonephritis. Kidney Int. 2000;57:499-509.

31. Foote A, Briganti EM, Kipen Y, Santos L, Leech M, Morand EF. Macrophage migration inhibitory factor in systemic lupus erythematosus. J Rheumatol. 2004;31:268-73.

32. Dumitru CA, Gholaman H, Trellakis S, Bruderek K, Dominas N, Gu X, Bankfalvi A, Whiteside TL, Lang S, Brandau S. Tumor-derived macrophage migration inhibitory factor modulates the biology of head and neck cancer cells via neutrophil activation. Int J Cancer. 2011;129:859-69.

33. Santos LL, Fan H, Hall P, Ngo D, Mackay CR, Fingerle-Rowson G, Bucala R, Hickey MJ, Morand EF. Macrophage migration inhibitory factor regulates neutrophil chemotactic responses in inflammatory arthritis in mice. Arthritis Rheum. 2011;63:960-70.

34. Becker H, Maaser C, Mickholz E, Dyong A, Domschke W, Gaubitz M. Relationship between serum levels of macrophage migration inhibitory factor and the activity of antineutrophil cytoplasmic antibody-associated vasculitides. Clin Rheumatol. 2006;25:368-72.

35. Wendt M, Borjesson O, Avik A, Bratt J, Anderstam B, Qureshi AR, Miller EJ, Gunnarsson I, Bruchfeld A. Macrophage migration inhibitory factor (MIF) and thyroid hormone alterations in antineutrophil cytoplasmic antibody (ANCA)-associated vasculitis (AAV. Mol Med. 2013:19:109-14.

36. Riedemann NC, Guo RF, Gao H, Sun L, Hoesel M, Hollmann TJ, Wetsel RA, Zetoune FS, Ward PA. Regulatory role of C5a on macrophage migration inhibitory factor release from neutrophils. J Immunol. 2004;173:1355-9.

37. Hao J, Lv TG, Wang C, Xu LP, Zhao JR. Macrophage migration inhibitory factor contributes to anti-neutrophil cytoplasmic antibody-induced neutrophils activation. Hum Immunol. 2016;77:1209-14.

38. van der Veen BS, Chen M, Muller R, van Timmeren MM, Petersen AH, Lee PA, Satchell SC, Mathieson PW, Saleem MA, Stegeman CA, et al. Effects of p38 mitogen-activated protein kinase inhibition on anti-neutrophil cytoplasmic autoantibody pathogenicity in vitro and in vivo. Ann Rheum Dis. 2011;70:356-65.

39. Kettritz R, Schreiber A, Luft FC, Haller H. Role of mitogen-activated protein kinases in activation of human neutrophils by antineutrophil cytoplasmic antibodies. J Am Soc Nephrol. 2001;12:37-46.

40. Schreiber A, Rolle S, Peripelittchenko L, Rademann J, Schneider W, Luft FC, Kettritz R. Phosphoinositol 3-kinase-gamma mediates antineutrophil cytoplasmic autoantibody-induced glomerulonephritis. Kidney Int. 2010;77:118-28.

41. Choi M, Rolle S, Rane M, Haller H, Luft FC, Kettritz R. Extracellular signalregulated kinase inhibition by statins inhibits neutrophil activation by ANCA. Kidney Int. 2003;63:96-106.

42. Lubetsky JB, Dios A, Han J, Aljabari B, Ruzsicska B, Mitchell R, Lolis E, Al-Abed $Y$. The tautomerase active site of macrophage migration inhibitory factor is a potential target for discovery of novel anti-inflammatory agents. J Biol Chem. 2002;277:24976-82.

43. Al-Abed Y, Dabideen D, Aljabari B, Valster A, Messmer D, Ochani M, Tanovic M, Ochani K, Bacher M, Nicoletti F, et al. ISO-1 binding to the tautomerase active site of MIF inhibits its pro-inflammatory activity and increases survival in severe sepsis. J Biol Chem. 2005;280:36541-4.

44. Hao J, Huang YM, Zhao MH, Chen M. The interaction between C5a and sphingosine-1-phosphate in neutrophils for antineutrophil cytoplasmic antibody mediated activation. Arthritis Res Ther. 2014;16:R142.

45. Hao J, Meng LQ, Xu PC, Chen M, Zhao MH. p38MAPK, ERK and PI3K signaling pathways are involved in C5a-primed neutrophils for ANCAmediated activation. PLoS One. 2012;7:e38317.

46. Hao J, Chen M, Zhao MH. Involvement of protein kinase C in C5a-primed neutrophils for ANCA-mediated activation. Mol Immunol. 2013;54:68-73.

47. Yuan J, Gou SJ, Huang J, Hao J, Chen M, Zhao MH. C5a and its receptors in human anti-neutrophil cytoplasmic antibody (ANCA)-associated vasculitis. Arthritis Res Ther. 2012:14:R140.

48. Rittirsch D, Flierl MA, Day DE, Nadeau BA, McGuire SR, Hoesel LM, Ipaktchi K, Zetoune FS, Sarma JV, Leng L, et al. Acute lung injury induced by lipopolysaccharide is independent of complement activation. J Immunol. 2008;180:7664-72.

\section{Publisher's Note}

Springer Nature remains neutral with regard to jurisdictional claims in published maps and institutional affiliations.

\section{Ready to submit your research? Choose BMC and benefit from}

- fast, convenient online submission

- thorough peer review by experienced researchers in your field

- rapid publication on acceptance

- support for research data, including large and complex data types

- gold Open Access which fosters wider collaboration and increased citations

- maximum visibility for your research: over $100 \mathrm{M}$ website views per year

At $\mathrm{BMC}$, research is always in progress.

Learn more biomedcentral.com/submissions 